\title{
PERÍMETROS IRRIGADOS, COMUNIDADE E SUSTENTABILIDADE: UMA REVISÃO DE LITERATURA
}

\author{
IRRIGATED PERIMETERS, COMMUNITY AND SUSTAINABILITY: A LITERATURE REVIEW
}

FRANKLIN ROBERTO DA COSTA

Professor da Universidade Estadual do Rio Grande do Norte (UERN)

e-mail: franklincosta@uern.br

\author{
BRUNO CÉSAR DIAS DE ALBUQUERQUE \\ Professor do Instituto Federal do Piauí (IFPI) \\ bruno.albuquerque@,ifpi.edu.br
}

\begin{abstract}
RESUMO: A agricultura, como atividade econômica que visa a sustentabilidade social e ambiental, vem passando por transformações geradas pela modernização do modo de produção e venda dos produtos gerados pelos agricultores e empresas de todo o país. Uma das tecnologias implantada foi o sistema de irrigação, que, por sua vez, permitiu, por parte do governo federal brasileiro, a construção dos chamados perímetros irrigados. No entanto, a implantação destes perímetros ocorreu de maneira diversa e com impactos positivos e negativos também diferenciados. Neste sentido, o objetivo do artigo foi analisar a sustentabilidade dos perímetros irrigados instalados no país, a partir de exemplos de alguns destes, principalmente no semiárido brasileiro. Foram realizadas leituras de diferentes materiais científicos, obtidos em sites de revistas, bibliotecas virtuais, além de livros sobre o tema em questão. Como resultado, percebeu-se que os perímetros irrigados no país foram implantados sobre a tutela do Estado, impondo modo de produção e consumo, gerando impactos negativos diretos na cultura das comunidades locais que foram contempladas com o empreendimento. Além disso, notou-se a insustentabilidade ambiental da atividade em todos os perímetros analisados, devido o mau uso dos recursos naturais neles existentes.
\end{abstract}

Palavras-chave: Perímetros irrigados. Comunidade local. Território. Sustentabilidade.

\begin{abstract}
Agriculture, as economic activity which aims at the social and environmental sustainability, has been undergoing transformations generated by the modernization of the production and sale of the products generated by farmers and companies across the country. One of the technologies deployed was the irrigation system, which, in turn, allowed by the Brazilian federal Government, the construction of so-called irrigated perimeters. However, the deployment of these perimeters occurred differently and with positive and negative impacts too differentiated. In this sense, the objective of the article was to analyze the sustainability of irrigated perimeters installed in the country, from examples of some of these, especially in the Brazilian semi-arid region. Different readings were performed scientific materials, obtained in sites of magazines, virtual libraries, in addition to books on the topic in question. As a result, it was noticed that the irrigated perimeters in the country were deployed on the guardianship of the State, enforcing mode of production and consumption, generating direct negative impacts on the culture of local communities that were included with the enterprise. In addition, it was noted the environmental
\end{abstract}


unsustainability of the activity in all perimeters analyzed, because the misuse of natural resources therein.

Keywords: Irrigated perimeters. local community. Territory. Sustainability.

\section{INTRODUÇÃO}

No semiárido brasileiro, através de políticas voltadas para o desenvolvimento rural, o governo federal vem, desde 1960, implantando perímetros irrigados como estratégia de expansão territorial da produção agrícola, seguindo uma perspectiva de desenvolvimento econômico e social. Estes perímetros são considerados regiões delimitadas pelo Estado para implantação de projetos públicos de agricultura irrigada que, em geral, possuem potencial para agricultura, solos férteis, presença hídrica, clima favorável e abundante força de trabalho (PONTES et al. 2013).

De acordo com Albuquerque (2008, p.38):

a delimitação da área foi denominada de perímetro e, pelo fato de se tratar de solos irrigáveis, foi acrescido o nome de irrigado. Assim, perímetro irrigado é uma área delimitada por solos irrigáveis, dividido em pequenas glebas, ocupadas por agricultores e empresários, ora chamados de colonos ou empresários, ora chamados de irrigantes familiares e irrigantes-empresários.

Segundo Scaloppi (1988), os perímetros irrigados são compostos por sistemas coletivos, inseridos em áreas e instalações necessárias ao desenvolvimento racional da agricultura irrigada, incluindo infraestrutura, bombeamento, adução, distribuição e aplicação de água às áreas irrigadas, desenvolvimento, adequação e melhoramento das terras, armazenamento de insumos e produtos agrícolas, comercialização, moradia e bem-estar social dos agricultores e seus dependentes.

As mudanças que surgiram a partir da implantação destas melhorias nos empreendimentos foram responsáveis por mudanças, também, no comportamento da sociedade local, modificando, inclusive, a identidade local, o ordenamento territorial e, consequentemente, a paisagem em vários lugares no país, principalmente na região semiárida (BRAGA \& FERRÃO, 2012; LIMA, 2005).

As mudanças observadas nestes cenários fizeram aparecer inúmeras publicações científicas relacionadas à discussão sobre os impactos sociais, econômicos e ambientais gerados a partir da implantação dos perímetros irrigados no país, mostrando resultados positivos e negativos deste tipo de sistema de produção nos últimos anos.

Isto é constatado, por exemplo, em artigos científicos (PONTES et al., 2013; BRAGA \& FERRÃO, 2012; LACERDA \& OLIVEIRA, 2007); assim como relatórios técnicos, teses, dissertações (OLIVEIRA, 2008; VASCONCELOS, 2010, entre outros) e artigos publicados em 
anais de eventos científicos, sites, blogs, tendo como referência os perímetros irrigados e seus impactos na implantação nestes territórios.

Destacam-se trabalhos como A irrigação no Brasil (IICA, 2008), que descreve a situação atual da irrigação no Brasil, formula hipóteses e apresenta recomendações para a constituição de uma nova visão do papel do setor público no desenvolvimento da agricultura irrigada no país. Em relação ao tema sustentabilidade, apresenta-se o artigo Sustentabilidade do perímetro irrigado Jabiberi, em que aplica indicadores de sustentabilidade para avaliação de perímetros irrigados, tomando como estudo o Perímetro Irrigado Jabiberi - SE.

Em se tratando da relação sociedade - perímetros irrigados têm-se, como exemplo, os trabalhos de Araújo (2014) e Silva (2006), que procuraram mostrar a relação dos colonos com o convívio com a seca e posteriormente com a implantação dos perímetros irrigados.

A partir destes exemplos têm-se como objetivo deste artigo, analisar por meio de avaliações críticas sistematizadas da literatura, os impactos sociais, econômicos, políticos e ambientais causados pela implantação dos perímetros irrigados no país.

\section{PERIMETROS IRRIGADOS E COMUNIDADE: CONSTRUÇÃO DE UM SONHO?}

A agricultura é uma técnica utilizada desde os primórdios da humanidade, com o objetivo de alimentar as sociedades. Com o avanço tecnológico, no decorrer dos anos, esta prática passou por um aumento na capacidade de produção, devido a necessidade de alimentação para uma população crescente no mundo. Neste sentido, no Brasil, o governo federal implantou uma série de perímetros irrigados em todo seu território, estabelecendo espaços vocacionados para o desenvolvimento da agricultura irrigada, considerado um processo que deveria promover a execução da prática agrícola sem que houvesse a possibilidade de déficit hídrico, além de buscar uma maior produção de alimentos, especialmente no Nordeste, visando amenizar problemas relacionados à seca e a busca da redução da pobreza.

Segundo Rigotto e Freitas (2014), foram construídos pelo Departamento Nacional de Obras Contra a Seca - DNOCS, entre os anos de 1968 e 1992, 38 perímetros públicos irrigados no Nordeste, mais especificamente na região conhecida como "polígono das secas". Priorizou-se, naquele momento, verbas para os projetos hídricos localizados nos vales úmidos, como Gurgueia e Parnaíba (PI), Acaraú e Jaguaribe (CE), Itapicuru e Rio das Contas (BA) e Açu e Apodi (RN).

Bursztyn (1995) e Diniz (1997) afirmam que os objetivos para implantação da irrigação pública pelo Governo Federal no Nordeste tinham, principalmente, como objetivos: introduzir um 
novo modelo de produção agrícola nessa região, via modernização da agricultura e incentivo a culturas agrícolas de maior rentabilidade, com destaque para a fruticultura irrigada, e minimizar os conflitos fundiários, desviando o debate da reforma agrária para a proposta de colonização que se desenvolveria por meio da seleção de irrigantes para ocupar os lotes dos perímetros públicos (Tabela 01).

Tabela 01: Perímetros irrigados instalados pelo DNOCS (1968 - 1989)

\begin{tabular}{|c|c|c|c|c|c|c|c|}
\hline Perímetro/Estado & $\begin{array}{l}\text { Área média } \\
\text { (ha) }\end{array}$ & $\begin{array}{c}\text { Quantidade } \\
\text { de } \\
\text { propriedades }\end{array}$ & Área total & $\begin{array}{c}\text { Ano de } \\
\text { implantação }\end{array}$ & $\begin{array}{l}\text { Ano de administração, } \\
\text { operação e } \\
\text { manutenção da } \\
\text { infraestrutura de uso } \\
\text { comum }\end{array}$ & Latitude & Longitude \\
\hline Jacurici/BA & 4,74 & 34 & 161,20 & 1968 & 1973 & 104158 & 395107 \\
\hline Morada Nova/CE & 20,3 & 785 & 3.677 & 1968 & 1970 & 51000 & 382200 \\
\hline $\begin{array}{c}\text { Icó-Lima } \\
\text { Campos/CE }\end{array}$ & 5,53 & 466 & 2.541 & 1969 & 1973 & 62500 & 385800 \\
\hline Fidalgo/PI & 2,08 & 86 & 179 & 1969 & 1973 & $\begin{array}{c}73245 \mathrm{a} \\
82715\end{array}$ & $\begin{array}{c}413219 a \\
422750\end{array}$ \\
\hline Sumé/PB & 5,82 & 47 & 273,65 & 1970 & 1970 & & \\
\hline Vaza Barris/BA & 10,06 & 168 & 1.487 & 1971 & 1973 & 095400 & 39007 \\
\hline $\mathrm{Ema} / \mathrm{CE}$ & 2,33 & 18 & 42 & 1971 & 1973 & 54800 & 381800 \\
\hline Quixabinha/CE & 3,11 & 94 & 293 & 1971 & 1972 & 73000 & 384500 \\
\hline Eng. Arcoverde/PB & 5,16 & 54 & 278,65 & 1971 & 1972 & 65430 & 373550 \\
\hline Cachoeira II/PE & 6,00 & 37 & 222 & 1971 & 1972 & 81002 & 381303 \\
\hline Caldeirão/PI & 3,79 & 100 & 379 & 1971 & 1972 & 41700 & 424700 \\
\hline São Gonçalo/PB & 10,33 & 480 & $2.267,09$ & 1972 & 1973 & - & - \\
\hline Boa Vista/PE & 3,79 & 27 & 102,50 & 1972 & 1975 & 80018 & 390743 \\
\hline Moxotó/PE & 7,92 & 596 & 6.375 & 1972 & 1977 & $\begin{array}{l}83000 \mathrm{a} \\
84800\end{array}$ & $\begin{array}{c}373800 \mathrm{a} \\
374300\end{array}$ \\
\hline Lagoas do Piaui/PI & 2,82 & 123 & 347 & 1972 & 1974 & 033000 & 423000 \\
\hline Várzea do Boi/CE & 2,74 & 114 & 313 & 1973 & 1975 & 55800 & 401500 \\
\hline Cruzeta/RN & 4,82 & 23 & 111 & 1973 & 1975 & 62500 & 364700 \\
\hline Itans/RN & 6,27 & 11 & 69 & 1973 & 1977 & - & - \\
\hline Pau dos Ferros/RN & 5,06 & 75 & 380 & 1973 & 1980 & 60700 & 381300 \\
\hline Sabugi/RN & 5,15 & 63 & 325 & 1973 & 1977 & - & - \\
\hline Ayres de Souza/CE & 4,26 & 45 & 192,00 & 1974 & 1978 & 34500 & 402700 \\
\hline Curu Paraipaba/CE & $\begin{array}{c}\text { 3,81 (empresa } \\
7,49)\end{array}$ & 796 & $3.279,00$ & 1974 & 1975 & 33000 & 391500 \\
\hline Forquilha/CE & 2,46 & 68 & 167,60 & 71974 & 1977 & 34600 & 401700 \\
\hline Custódia/PE & 4,30 & 50 & 215 & 1974 & 1975 & 80500 & 373730 \\
\hline $\begin{array}{c}\text { Curu- } \\
\text { Pentecoste/CE }\end{array}$ & 4,13 & 174 & 743 & 1974 & 1975 & $\begin{array}{c}340 \text { a } 3 \\
5118\end{array}$ & $\begin{array}{c}391019 \mathrm{a} \\
391813\end{array}$ \\
\hline Jaguaruama/CE & 5,05 & 40 & 202,00 & 1975 & 1977 & 41000 & 380017 \\
\hline Gurguéia/PI & 9,52 & 194 & 1.954 & 1975 & 1977 & 84904 & 441326 \\
\hline Brumado/BA & 5,27 & 289 & $1.523,40$ & 1977 & 1986 & $\begin{array}{c}1330 \text { a } 13 \\
45\end{array}$ & $\begin{array}{c}4145 \text { a } 42 \\
20\end{array}$ \\
\hline $\begin{array}{l}\text { Tabuleiros de } \\
\text { Russas/CE }\end{array}$ & $\begin{array}{l}8 \text { a } 145 \\
\text { (pequeno } \\
\text { produtor a } \\
\text { empresa) }\end{array}$ & 662 & 10.564 & 1980 & 1987 & 53720 & 380708 \\
\hline Baixo-Acaraú/CE & 15,144 & 571 & 8.816 & 1983 & 2001 & & \\
\hline Araras Norte/CE & $\begin{array}{c}9,00 \text { (empresa } \\
302,90)^{*}\end{array}$ & 103 & $1.345,80$ & 1987 & 1988 & 40900 & 403200 \\
\hline $\begin{array}{l}\text { Jaguaribe- } \\
\text { Apodi/CE }\end{array}$ & $\begin{array}{c}7,85 \text { (empresa } \\
50,95)\end{array}$ & 251 & $2.834,80$ & 1987 & 1989 & 52000 & 380500 \\
\hline $\begin{array}{c}\text { Platôs de } \\
\text { Guadalupe/PI }\end{array}$ & $\begin{array}{l}\text { (7,05 peq. } \\
\text { Produ tor) } \\
(109,21 \\
\text { empresa) }\end{array}$ & 82 & 2.009 & 1987 & 1993 & 64713 & 433408 \\
\hline $\begin{array}{c}\text { Tabuleiros } \\
\text { Litorâneos/PI }\end{array}$ & $\begin{array}{c}\text { (8,07 peq. } \\
\text { Produtor; } \\
\text { 18,50-6 } \\
\text { eng.agron.; } \\
\text { 95,35-17 } \\
\text { empresas }\end{array}$ & 90 & 2.273 & 1989 & 1998 & 25500 & 415000 \\
\hline Baixo-Açu/RN & $\begin{array}{c}\text { Peq.produtor } \\
-8,52\end{array}$ & 197 & $5.167,95$ & 1989 & 1994 & $\begin{array}{l}52000 \mathrm{e} \\
53000\end{array}$ & $\begin{array}{c}363000 \mathrm{a} \\
365000\end{array}$ \\
\hline
\end{tabular}




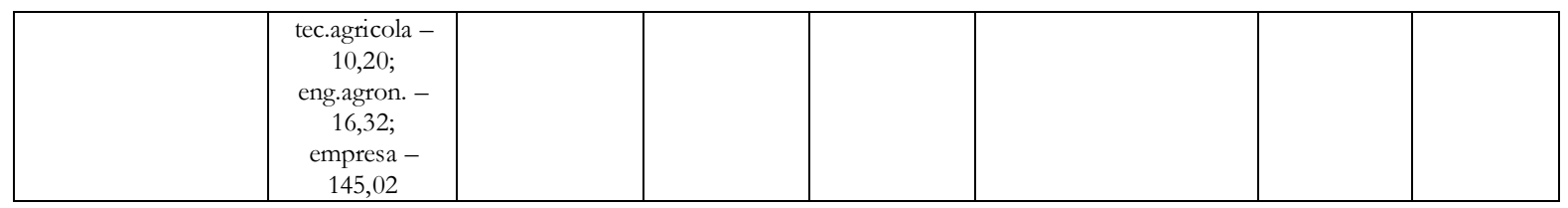

Fonte: DNOCS, 2014.

A tabela 01 foi organizada seguindo a data de criação dos perímetros irrigados pelo DNOCS entre os anos de 1968 e 1989. Os mesmos se caracterizam por uma heterogeneidade de atividades (diferentes tipos de produção agropecuária), assim como de tipo de proprietários. Estes últimos são, em sua maioria, pequenos produtores rurais que atuam em pequenas áreas (lotes) tendo, em média, cerca de 5 hectares para a produção. A implantação destes datam, em grande parte, do início da década de 1970, apesar de haver 04 (quatro) perímetros implantados no final da década de 1960 (Jacurici/BA, Morada Nova/CE, Icó-Lima Campos/CE, Fidalgo/PI) e outros 07 (sete) implantados na década de 1980 (Tabuleiros de Russas/CE, Baixo-Acaraú/CE, Araras Norte/CE, Jaguaribe-Apodi/CE, Platôs de Guadalupe/PI, Tabuleiros Litorâneos/PI, BaixoAçu/RN.

O maior perímetro irrigado é o Baixo-Acaraú, localizado no Estado do Ceará, com 8.816 hectares, dividido em 541 propriedades, distribuídos entre pequenos agricultores (470), profissionais da Área de Ciências Agrícolas: (38) e empresas (33). As maiores médias de hectares produzidos são das empresas $(60,0)$ e a menor dos pequenos produtores $(8,0)$ (DNOCS, 2014).

Cita-se o exemplo acima para constatar uma das realidades de alguns perímetros irrigados gerenciados pelo DNOCS, que é a concentração das terras nas mãos das empresas. Enquanto a média de terras nas mãos dos pequenos produtores está em torno de 5 (cinco) hectares, as 77 empresas detém, em média, mais de 100 hectares por propriedade.

Além do DNOCS, outro importante órgão responsável pela instalação de perímetros irrigados no país é a Companhia de Desenvolvimento dos Vales do São Francisco e do Parnaíba CODEVASF. Caracteriza-se como uma empresa pública, vinculada ao Ministério da Integração Nacional, que promove o desenvolvimento e revitalização de bacias hidrográficas dos rios São Francisco, Parnaíba, Itapecuru e Mearim. O principal objetivo é a utilização sustentável dos recursos naturais e estruturação de atividades produtivas, visando a inclusão econômica e social (CODEVASF, 2014).

Atualmente a CODEVASF gerencia 34 projetos que estão em produção, 6 (seis) em implantação e 3 (três) em estudo, distribuídos em 5 (cinco) estados (Alagoas, Bahia, Minas Gerais, Pernambuco, Sergipe), totalizando 48 projetos. No entanto, atua efetivamente em 25 projetos públicos. 
Tabela 02: Perímetros irrigados instalados pela CODEVASF $(1968$ - 2010)

\begin{tabular}{|c|c|c|c|}
\hline Perímetro/Estado & $\begin{array}{l}\text { Área total } \\
\text { (hectares) }\end{array}$ & $\begin{array}{c}\text { Ano de } \\
\text { implantação }\end{array}$ & Ano de co-gestão \\
\hline Bebedouro (PE) & 2418 & 1968 & 1998 \\
\hline Estreito I/III/IV (BA) & 8013 & $\begin{array}{c}1975(\mathrm{I} \\
\mathrm{eIII}) / 1985(\mathrm{IV}) \\
\end{array}$ & 1995 \\
\hline Mandacaru (BA) & 450 & 1971 & 2000 \\
\hline Ceraíma (BA) & 408 & 1973 & 1998 \\
\hline Jaíba - Etapa I (MG) & 26030 & 1975 & 1988 \\
\hline Propriá (SE) & $\begin{array}{c}1177 \text { (lotes } \\
\text { empresariais) }\end{array}$ & 1976 & 1997 \\
\hline Betume (SE) & 2860 & 1978 & 1998 \\
\hline Piloto Formoso (BA) & 408 & 1978 & 1987 \\
\hline Gorutuba (MG) & 4734 & 1978 & 1993 \\
\hline Itiúba (AL) & 900 & 1978 & 1998 \\
\hline Lagoa Grande (MG) & $\begin{array}{l}1538 \text { (lotes } \\
\text { empresariais) }\end{array}$ & 1978 & 1993 \\
\hline $\begin{array}{c}\text { São Desidério/Barreiras Sul } \\
(\mathrm{BA})\end{array}$ & 1718 & 1978 & 1995 \\
\hline Pirapora (MG) & $\begin{array}{c}1236 \text { (lotes } \\
\text { empresariais) }\end{array}$ & 1979 & 1987 \\
\hline Tourão (BA) & 14237 & 1979 & 1988 \\
\hline Curaçá (BA) & 4203 & 1980 & 1990 \\
\hline Maniçoba (BA) & 4.160 & 1980 & 1990 \\
\hline Cotiguiba/Pindoba (SE) & 2232 & 1982 & 1998 \\
\hline Boacica (AL) & 2762 & 1984 & 1997 \\
\hline Senador Nilo Coelho (PE) & 18563 & 1984 & 1989 \\
\hline Manga de Baixo (PE) & 93 & 1987 & Não iniciada \\
\hline Formoso"A"e "H"(BA) & 11751 & 1989 & 1988 \\
\hline Glória (BA) & 368 & 1992 & Não iniciada \\
\hline Apolônio Sales/PE & 3.845 & 1993 & Não iniciada \\
\hline Barreiras Bloco I/PE & 250,35 & 1993 & Não iniciada \\
\hline Rodelas (BA) & 1210 & 1993 & Não iniciada \\
\hline Brígida (PE) & 1435 & 1994 & Não iniciada \\
\hline Icó Mandantes (PE) & 2187 & 1994 & Não iniciada \\
\hline Pedra Branca (BA) & 2731 & 1994 & Não iniciada \\
\hline Mirorós (BA) & 2159 & 1996 & 1998 \\
\hline Fulgêncio (PE) & 4716 & 1998 & Não iniciada \\
\hline Nupeba/Riacho Grande (BA) & 2853 & 1998 & 2000 \\
\hline Salitre - Etapa I (BA) & 5099 & 1998 & Não informado \\
\hline Barreiras Norte (BA) & 1652 & 1999 & Em processo \\
\hline Barreiras Bloco II/PE & 466,5 & 2010 & Não iniciada \\
\hline
\end{tabular}

Fonte: CODEVASF, 2014.

A tabela 02 também foi organizada por ano de criação e observa-se que até o perímetro irrigado Senador Nilo Coelho (PE), todos tiveram sua co-gestão iniciadas, em que a CODEVASF está orientando e financiando a execução das produções agrícolas pelo sistema de irrigação. Além disso, observou-se que alguns destes perímetros têm, em sua maioria ou na totalidade, a gestão realizada por empresas, proprietárias das terras. Podem-se citar, como exemplos, os perímetros Tourão, Maniçoba e Salitre, no Estado da Bahia e o Jaíba (etapa I), no Estado de Minas Gerais. 
Por outro lado, há perímetros cujos proprietários são, na sua maioria, pequenos agricultores, como São Desidério/Barreiras Sul, Mirorós (BA), Nupeba/Riacho Grande (BA), Senador Nilo Coelho (PE) e Senador Nilo Coelho (PE).

Vale salientar que a ação do Estado para a implantação de áreas irrigáveis iniciou-se em 1877, decorrente de uma grande seca na região. Portanto, antes da ação do governo federal a partir dos órgãos supracitados. O objetivo era amenizar os impactos causados pela seca, porém, "resumindo-se a arranjos e fórmulas improvisadas" (AGUIAR NETTO et al, 2006). "Essa ação emergencial e assistencialista passa a ser a regra geral no interior das políticas públicas para a região até a década de 1940" (ROBOCK, 1992).

Percebe-se que a presença do Estado como promotor das transformações tecnológicas e econômicas foi responsável pelas mudanças no comportamento das comunidades, principalmente na organização social e espacial das áreas onde foram implantados os perímetros irrigados (DINIZ, 2002).

A consequência direta desta politica pública é vista a partir do que afirma Rolim (2006), na qual a implantação de uma área agricultável com técnicas modernas de irrigação impõe uma nova organização espacial que modifica o quadro social, pois, ao se tornar colono, o antigo proprietário tem sua estrutura de vida alterada, resultando em um impacto social e cultural dessa imposição.

Estas transformações no espaço ocasionam, portanto, impactos ambientais, sociais e econômicos que podem se tornar irreversíveis. De acordo com Almeida \& Costa (2014), observase determinados problemas nas técnicas de produção da agricultura irrigada, tais como: a pouca ou nenhuma produtividade do solo; problemas de saúde das pessoas que convivem na área, além das que consomem produtos irrigados; desperdício de água durante a prática da irrigação por determinadas técnicas; assim como o desmatamento provocado pela troca da área nativa pela plantação dos cultivos agrícolas e uso para lenha.

Outro ponto importante, na discussão sobre o tema perímetros irrigados, está na associação que diversos autores fazem com o fenômeno climático da seca e a presença do Estado na região Nordeste, sendo vista sempre como uma "catástrofe" e não como uma característica do clima regional presente nesta área (ROLIM, 2006; SILVA, 2006; LACERDA e OLIVEIRA, 2007; CARVALHO, 2009; PONTES et al, 2014). Para resolver este problema, segundo os autores, o Estado vem buscando a redução da pobreza com a construção de açudes, objetivando oferecer novas oportunidades de trabalho com a utilização de novas técnicas de produção agrícola.

Rolim (2006) afirma que o objetivo principal da construção dos perímetros irrigados foi somente reduzir a pobreza, pois as implantações dos projetos de irrigação estavam ligadas às 
construções de açudes, sem uma preocupação maior com a produtividade, conhecimento, tecnologia, crédito, mercado e formação de recursos humanos.

No entanto, segundo Lima (2005), há um novo discurso sobre o semiárido (região onde foram implantados a maioria dos perímetros irrigados no país), realizado por uma parcela do meio empresarial e administração pública, valorizando o sol intenso, baixos índices pluviométricos e a média e alta temperatura o ano inteiro. Segundo Castro (1996), a constante temperatura e luminosidade são fundamentais para o desenvolvimento da fruticultura irrigada, turismo ou outra atividade que exijam tais características naturais.

Ao tratar desta característica natural, Santana (2003) afirma que "as condições edafoclimáticas do semi-árido não mudaram, mudou o conhecimento, mudou a tecnologia, mudou a capacidade de conviver com a nossa realidade e descobrir, na sua diversidade, as suas potencialidades".

O reflexo destas mudanças se dá na forma como a sociedade se comporta diante desta politica pública adotada em seus territórios. Entende-se, neste contexto, território como o espaço vivido, fundamento do trabalho, das trocas materiais e imateriais (SANTOS, 2008). Ao analisar este conceito, Vasconcelos (2010) afirma que este território, produzido pela sociedade, representa a história que está sempre por se refazer, assim como também é um processo que amanhã tornase outra situação.

A referida autora também é feliz em sua construção teórica, quando utiliza o conceito de território utilizado por Oliveira (2004), relacionando o conceito às transformações espaciais do campo. O autor afirma que a configuração histórica do território acontece por meio da luta entre classes sociais, evidenciando a "territorialização do capital monopolista", a partir, por exemplo, do assalariamento dos antigos colonos, ou a "monopolização do território pelo capital monopolista". Vasconcelos (2010) explica que tal monopolização se aplica quando o capital não consegue se "territorializar", monopoliza o território da produção familiar, sujeitando estes agricultores ao modo de produção capitalista, fornecendo produções e bens industrializados no espaço do campo. É neste interim que ocorre os conflitos socioespaciais.

Neste caso, Pontes et al (2013) afirmam que foram expressivos os conflitos socioambientais no perímetro irrigado de Santa Cruz - RN (Mapa 01), demonstrando os impactos no processo saúde-doença em comunidades camponesas. Além da relação saúde-doença, outro problema enfrentado pelo perímetro Santa Cruz foi colocado por um grupo de movimentos sociais (Articulação Nacional de Agroecologia - ANA) visando a sua não implantação. 


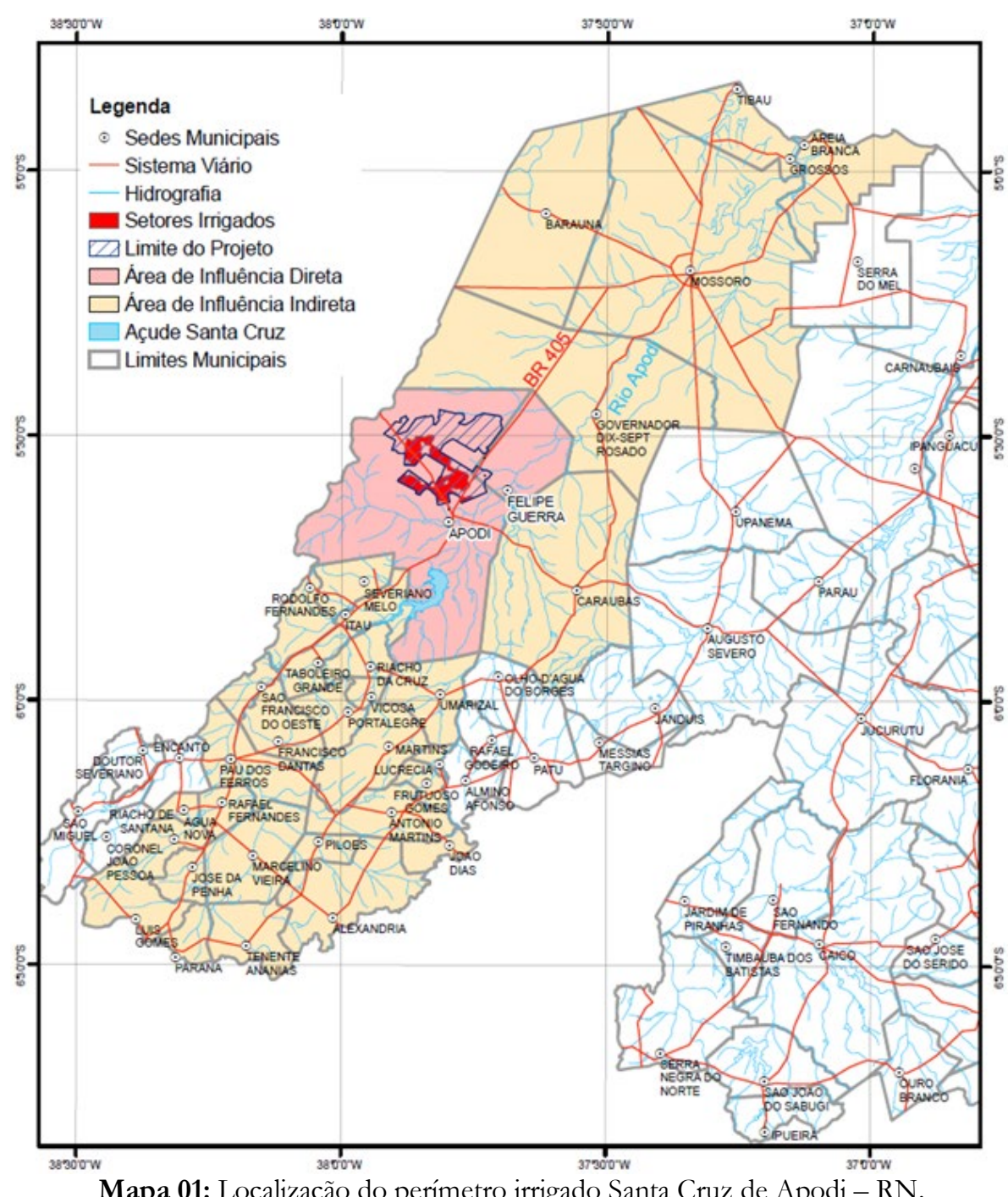

Fonte: http://blogsertaopotiguar.blogspot.com.br/2011/10/o-polemico-projeto-de-irrigacao-do.html, 2014.

Dentre as justificativas, o grupo afirma que o projeto beneficiará 05 empresas do agronegócio; expulsará centenas de famílias de pequenos agricultores e agricultoras de suas terras; desaparecerá algumas comunidades da chapada; contaminará as terras, águas e a população; acabará com a produção de mel, da caprinocultura, da avicultura, assim como a produção agroecológica das comunidades da chapada e provocará, a exemplo de outros perímetros irrigados, a miséria, a prostituição e a violência no município de Apodi (ANA, 2011)

Araújo, Godrim e Souza (2007) analisaram a baixa participação dos agricultores familiares do Projeto Jaíba (Minas Gerais) na gestão e produção local e justificam esta afirmativa pela falta de consideração dos aspectos culturais, sociais e políticos, gerando graves problemas, dentre as quais a desorganização social e a baixa participação dos agricultores em iniciativas que necessitassem de 
gestão social. Afirmam também que esses fatores influenciaram direta e negativamente a comercialização, acesso a crédito, empoderamento e a construção de uma identidade com o perímetro estudado.

Silva (2006), ao analisar as principais concepções e alternativas de intervenção regional, visando identificar os fundamentos para uma proposta alternativa de desenvolvimento sustentável no semiárido brasileiro, afirma que o regime adotado para a implantação dos perímetros irrigados tinha reflexos nas formas autoritárias de gerência, impedindo a contestação ao modelo tecnológico e gerencial. Para sustentar essa afirmativa, utiliza-se das palavras de Araújo (1997, p.179):

Com o advento dos governos militares, o DNOCS é encarregado de promover a implantação de perímetros públicos de irrigação, segundo modelização que the foi imposta, e que viria, posteriormente, a ser objeto de críticas de todos os matizes, apontada como imprópria para o desenvolvimento da atividade, em face, tanto do caráter autoritário de que se revestiu a sua implantação, como por aspectos clientelistas e paternalistas, presentes ao modelo.

Silva (2006) afirma que há um rompimento com os princípios da autogestão cooperativista, pois são as equipes técnicas do Órgão do Governo que definiam o processo de produção em nome dos cooperados, desde os tipos de produtos, da área a ser cultivada, da tecnologia adotada, até a forma de produção. Esta forma de "administração" do governo gerou uma dependência direta dos colonos com o poder público, justificando a política assistencialista observada em muitos perímetros até os dias atuais.

\section{PERIMETROS IRRIGADOS E DESENVOLVIMENTO LOCAL: CONFLITOS PARA A BUSCA DA SUSTENTABILIDADE}

O desenvolvimento local, a partir da implantação de politicas públicas, independente da modalidade, precisa estar adequado a um modelo de desenvolvimento endógeno, observando as peculiaridades de cada comunidade e sua vocação para o crescimento (desenvolvimento) social, econômico e ambiental. Entende-se como desenvolvimento endógeno, o uso de recursos localmente disponíveis, tais como as potencialidades da ecologia local, da força de trabalho, conhecimentos e modelos locais para articular produção e consumo (LONG e VAN DER PLOEG, 1994)

Segundo Santos (2012), ao contrário da modernização, o ponto de referência do desenvolvimento endógeno são as características socioculturais, ecológicas e econômicas dos locais, em que pode servir como suporte na hora de estabelecer relações. 
Neste sentido, autores como Guzmán Casado et al. (2000), Calatrava (1995), Long e van der Ploeg (1994), Barroso (2009) e Santos (2012) entendem que, para o desenvolvimento rural é necessário alcançar a integralidade, a partir do aproveitamento das potencialidades dos distintos estabelecimentos dos setores econômicos necessários para permitir acesso aos meio de vida da população, buscando assim o seu bem estar; harmonia e equilíbrio entre os sistemas econômicos e ecológicos; autonomia de gestão e controle do processo de desenvolvimento, no tocante a gestão e controle pelos próprios habitantes dos perímetros; minimização das externalidades negativas nas atividades produtivas, evitando a degradação dos recursos naturais; manutenção e potencialização dos circuitos curtos, ou seja, manter e potenciar, na medida do possível, os mercados locais; utilização do conhecimento local vinculado aos sistemas tradicionais de manejo dos recursos naturais e a pluriatividade, seletividade e complementaridade das rendas, referindo-se a complementaridade da renda como forma de ação social coletiva presentes na comunidade.

A partir destes princípios observa-se que, para que houvesse um desenvolvimento rural local, a implantação dos perímetros irrigados seria um dos principais projetos políticos adotado no país, principalmente a partir da década de 60, visando a melhoria de qualidade de vida para a população rural ali instaladas. No entanto, a implantação dos mesmos passou (e vem passando) por conflitos de ordens diversas. Seja pelo modo de produção, escolha das famílias, sustentabilidade ambiental e financeira, as implantações destes projetos não são vistos por todos como uma alternativa para o desenvolvimento local.

Segundo Lima (2005), mais do que fixar o homem no campo, o principal objetivo foi expandir o modo de produção capitalista, escolhendo as melhores áreas para a reprodução do consumo. Neste caso, invadindo territórios, impondo normas e transformando a vida local.

Neste sentido, Pontes et al (2013) apresentam 02 (dois) casos de conflitos para implantação de perímetros irrigados na região nordeste brasileira, especificamente nos estados do Ceará e Rio Grande do Norte. No Estado do Ceará, o incentivo ao agronegócio vem provocando a desterritorialização da Chapada do Apodi, a partir de ações coordenadas pelo próprio estado, que incentiva a produção para exportação, a partir do fornecimento de água para cultivo.

Além disso, os autores colocam que há contaminação pelo uso de agrotóxicos, extinção de comunidades inteiras pela desocupação forçada, inclusive com violência, obrigando as famílias a abandonarem as casas; inserção de culturas externas e insegurança.

No estado do Rio Grande do Norte, particularmente na continuação da Chapada do Apodi, o perímetro irrigado Santa Cruz - RN passou por conflitos em sua instalação, pois a comunidade local (camponesa) sempre se destacou por desenvolver projetos de base agroecológica, com o apoio 
de movimentos sociais, entidades sindicais, pastorais e ambientalistas, além de setores das universidades existentes na região, permitindo a construção de um modo de vida e trabalho da agricultura familiar camponesa diferente da cultura e lógica capitalista (Pontes et al., 2013).

Assim como ocorreu no perímetro em terras cearenses, os autores afirmam que no perímetro irrigado Santa Cruz - RN,

amplas transformações territoriais repercutem de forma diversificada na saúde, como o comprometimento da biodiversidade e do acesso a recursos naturais, como a terra e a água; desagregação familiar e novos padrões de gênero; a atração de grandes contingentes de trabalhadores de outras localidades para o território, o que gera novas demandas de saneamento, moradia, educação, lazer, transporte. Associam-se também a esses processos migratórios a violência, acidentes de trânsito, doenças sexualmente transmissíveis e AIDS, consumo de álcool e drogas ilícitas, doenças mentais e sofrimento psíquico, gravidez precoce, entre outros (Pontes et al, 2013, p.3220).

O resultado da implantação dos perímetros nesta região mostra o quanto é complexo a relação entre projetos institucionais e a identidade local, atrelado à construção de novas territorialidades, sem haver alterações na cultura e hábitos tradicionais.

Lima et al (2009) demonstram a ação do Estado como exemplo da prática de inserção de políticas de desenvolvimento local a partir da implantação de perímetros irrigados, neste caso o perímetro irrigado Jaguaribe Apodi. Afirmam que o favorecimento a entrada de uma empresa produtora de frutas (melão e abacaxi para exportação) foi responsável pela expropriação de terras, precarização nas relações de trabalho, des(re)territorialização de agricultores familiares, ampliação da pobreza, além da fragilização da saúde do homem e da natureza, pelo uso de agrotóxicos na produção. Exemplo disso é destacado na comunidade km69, que correspondia a cerca de 70 famílias e hoje está com apenas 5 (cinco). As que foram expulsas procuraram se deslocar para cidades com Limoeiro do Norte e Quixeré, inseridos agora em uma nova cultura para conseguir manter condições de vida satisfatórias.

Em outro trabalho, Oliveira (2008) analisa a sustentabilidade do perímetro irrigado Baixo Acaraú, no Estado do Ceará, a partir de questões-socioeconômicas, ambientais e institucionais, tendo como metodologia um conjunto de índices de sustentabilidade. A autora conclui que não há uma autosustentabilidade e que fatores como habitação, saúde, educação e questões ambientais são itens que precisam passar por reformulações, já que a comunidade local demonstrou estar insatisfeita com a situação naquele momento.

Assim como Oliveira (2008), Carvalho (2009) avalia a sustentabilidade da agricultura familiar nos perímetros irrigados de Apolônio Sales e Icó-Mandantes, localizados nos municípios 
de Petrolândia e Floresta, no Estado de Pernambuco. A autora afirma que há uma sustentabilidade regular nas dimensões social, econômica e politico-institucional e deficiente, assim como o Baixo Acaraú - CE, na dimensão ecológica.

Conclui mostrando que, para se atingir a sustentabilidade requerida, se faz necessário intensificar a participação dos produtores nas organizações sociais, promover gestão participativa dos projetos, definir sistemas de comercialização, fiscalizar áreas protegidas, racionalizar o uso da água, entre outras. Isto porque, segundo a autora, não há uma adequação dos perímetros irrigados com a multidimensionalidade exigida pela inter-relação entre as dimensões ecológica, social, econômica e politico-institucional para a sustentabilidade da agricultura familiar.

\section{CONSIDERAÇÕES FINAIS}

Percebeu-se, nos trabalhados analisados, que existem potenciais para a adaptação dos perímetros irrigados frente às dinâmicas econômicas e sociais, a partir desta interface com centros urbanos regionais, principais responsáveis pelo consumo da produção agrícola nestas áreas. Mas, ao mesmo tempo, foi possível observar que há uma capacidade limitada em gerar um desenvolvimento local com bases sustentáveis, uma vez que estão vulneráveis e dependentes das cadeias e dos processos exógenos, e, neste sentido, não conseguem exercer praticamente nenhuma influência para se manter a sustentabilidade sonhada pela comunidade local.

Além disso, a necessidade de aumento da produção, em detrimento do aumento do consumo humano, faz com que impactos ambientais negativos sigam a mesma proporcionalidade de aumento, prejudicando a sustentabilidade do meio como um todo, e particularmente, gerando uma perda de qualidade de vida para a população local e a deterioração dos recursos naturais, cada vez mais escassos no planeta.

Convém repensar o caminho escolhido para a execução das atividades nos perímetros irrigados, pois, o que se vê é a insustentabilidade do modelo de desenvolvimento atual, incapaz de manter a qualidade social e ambiental, especialmente neste momento em que passamos por um grave problema da falta de recursos hídricos, ocasionada por questões climáticas, em várias partes do país, mas também pelo uso pouco racional por parte da sociedade brasileira.

\section{REFERÊNCIAS BIBLIOGRÁFICAS}

AGUIAR NETTO, A.O.; MACHADO, R.; VARGAS, M.A.M. Sustentabilidade do perímetro irrigado Jabiberi. Revista RA'E GA, Curitiba, n.12, p.153-159, 2006. 
ALBUQUERQUE, J. A. Avaliação do programa de transferência da gestão em perímetros públicos de irrigação: o caso de Morada Nova. 2008. 94 f. Dissertação (Mestrado) - Curso de Pós- Graduação em Avaliação de Políticas Públicas, Universidade Federal do Ceará, Fortaleza, 2008.

ANA - Articulação Nacional de Agroecologia. Não a instalação do perímetro irrigado no município de Apodi - $\mathbf{R N}$. Disponível em: http://www.agroecologia.org.br/index.php/noticias/266-nao-a-instalacao-do-perimetroirrigado-no-municipio-de-apodi-rn. Acesso em: 10 dez.2014.

ARAÚJO, H.S. Os recursos hídricos e o desenvolvimento sustentável do Semi-árido nordestino: a contribuição do DNOCS. In: SIMPÓSIO BRASILEIRO SOBRE MEIO AMBIENTE E DESENVOLVIMENTO SUSTENTÁVEL DO SEMI-ÁRIDO, 1, 1997, Mossoró - RN. Anais...Mossoró/RN: UERN, 1997c, p.172 a 222.

ARAÚJO, T.C.A.; GODRIM, M.D; SOUZA, V.S. A organização social da agricultura familiar do projeto Jaíba - MG como desafio para o desenvolvimento local sustentável. XIV Congresso da SOBER: conhecimentos para agricultura do futuro. Curitiba - PR. Anais..., 2007.

ARAÚJO, L.F.A. Agricultura familiar na visão dos colonos do perímetro irrigado de Sumé - Paraíba. Monografia (Especialização em Fundamentos da Educação: Práticas Pedagógicas Interdisciplinares). Universidade Estadual da Paraíba. Paraíba, 2014.

BARROSO, J.A.V. Diagnóstico ecológico-econômico da bacia do Rio Cauamé no estado de Roraima, com a utilização de sistema de informação geográfica para o desenvolvimento sustentável. Dissertação (Mestrado profissional interinstitucional em Economia). Universidade Federal do Rio Grande do Sul, Faculdade de Ciências Econômicas, Programa de Pós-graduação em Economia, Porto Alegre - RS, 2009.

BRAGA, L. M. M.; ARGOLLO FERRÃO, A. M.. Patrimônio rural e paisagem da produção agrícola no Baixo Jaguaribe [Ceará]: planejamento e gestão de recursos hídricos. In: SEMINARIO DE PAISAJES CULTURALES UDELAR/UPC [Conpadre n.11/2012], 2., 2012, Montevideo [Uruguay]. Actas...Montevideo: Red Conpadre, 2012. p. 01-12. Disponível em:<www.conpadre.org. Acesso em: 05 nov. 2014.

BURSZTYN, M. O poder dos donos: planejamento e clientelismo no Nordeste. Petrópolis: Vozes, 1985.

CALATRAVA, J.R. Actividad agraria y sustentabilidade em el desarrollo rural. In: RAMOS, E.L.; VILLALÓN, J.C. Hacia un nuevo sistema rural. Madrid: MAPA, 1995.

CARVALHO, R.M.C.M.O. Avaliação dos perímetros de irrigação na perspectiva da sustentabilidade da agricultura familiar no semi-árido Pernambucano. Tese (Doutorado). Programa de Pós Graduação em Engenharia Civil. Universidade Federal de Pernambuco, 2009.

CASTRO, Iná Elias de. Seca versus seca: novos interesses, novos territórios, novos discursos no Nordeste. In: CASTRO, Iná Elias de et al. (org.). Brasil: questões atuais da reorganização do território. Rio de Janeiro: Bertrand, 1996, p. 283-323.

COMPANHIA DE DESENVOLVIMENTO DOS VALES DO SÃO FRANCISCO E DO PARNAÍBA - CODEVASF. Perímetros irrigados. 
DEPARTAMENTO NACIONAL DE OBRAS CONTRA A SECA - DNOCS. Perímetros irrigados. Disponível em: http://www.dnocs.gov.br/ dnocs/doc/canais/perimetros irrigados.htm. Acesso em: 10 dez. 2014.

DINIZ, A. S. A construção dos perímetros irrigados e a criação de novas territorialidades no sertão. In:___ ELIAS, D.; SAMPAIO, L.F.; DINIZ, A.S. Modernizações excludentes. Coleção paradigmas da agricultura Cearense. Fortaleza: Edições Democráticas Rocha, 2002. p. 39 a 59.

Território controlado - território (re) criado: os laços e rupturas das relações Estado e Irrigantes. Dissertação de Mestrado. Recife / UFPE. 1997.

FRAGA, R.R.O. Sustentabilidade rural e políticas públicas: a reestruturação produtiva da região canavieira do norte fluminense. X Encontro Nacional de Geógrafos da América Latina. São Paulo. Anais...., São Paulo, 2005.

GOMES, R.A. Representação social e cultura para aprender uma qualidade de vida. Sociedade em Debate. Pelotas - RS, n.9, v.1, p.55-82, mar. 2003.

GUZMÁN CASADO, G. et al. Introducción a la agroecologia como desarrollo rural sostenible. Madrid: Edicionnes Mundi-Prensa, 2000.

LACERDA, N.B.; OLIVEIRA, T.S. Agricultura irrigada e a qualidade de vida dos agricultores em perímetros do Estado do Ceará, Brasil. Revista Ciência Agronômica. Fortaleza, v.38, n.2, p.216223, 2007.

LIMA, G. P. A produção do território no perímetro irrigado Curu-Pentecoste. (Dissertação Mestrado Acadêmico em Geografia) Universidade Estadual do Ceará, Centro de Ciências e Tecnologia. Fortaleza, 2005.

LIMA, L. C. ; FREITAS, B. M. C. ; VASCONCELOS, T. S. L. ; COSTA, C. R. R. . Reestruturação socioespacial em lugares subdesenvolvidos: caso do Nordeste Brasileiro. In: $12^{\circ}$ encuentro de geógrafos de América Latina, 2009, Montevideo-Uruguay. Caminando en una América Latina en transformación. Anais....Montevideo- Uruguay, 2009.

LONG, N. and PLOEG J. D. van der. Heterogeneity, actor and structure: towards a reconstitution of the concept of structure. In: BOOTH, D. (ed) Rethinking Social Development: theory, research and practice. England, Longman, p. 62-90, 1994.

OLIVEIRA, A.C. Direitos e/ou povos e comunidades tradicionais: noções de classificação em disputa. Revista Desenvolvimento e Meio Ambiente. Paraná - PR, v.27, p.71-85, jan/jun. 2013.

OLIVEIRA, J. A. L. Análise da (auto) sustentabilidade do Perímetro Irrigado Baixo Acaraú: um estudo de caso. Dissertação (Mestrado) Economia Rural - Universidade Federal do Ceará. Fortaleza, 2008.

PONTES, A. G. V. et al . Os perímetros irrigados como estratégia geopolítica para o desenvolvimento do semiárido e suas implicações à saúde, ao trabalho e ao ambiente. Ciênc. saúde coletiva, Rio de Janeiro, v.18, n. 11, Nov. 2013. Available from $<$ http://www.scielo.br/scielo.php?script $=\quad$ sci_arttext\&pid=S141381232013001100012\&lng=en\&nrm=iso >. Acesso em: 10 Nov. 2014. 
RIGOTTO, R.M.; FREITAS, B.M.C. Dossiê perímetros irrigados. Perímetros irrigados e a expansão do agronegócio no campo: quatro décadas de violação de direitos no semiárido. Disponível em: http://dossieperimetrosirrigados.net. Acesso em: 12 dez. 2014.

ROBOCK, S. H. Algumas reflexões históricas sobre o desenvolvimento de uma região semiárida: o Nordeste do Brasil. Brasília: [s.n.], 1992.

ROLIM, J.B.S. Sistemas técnicos e sustentabilidade: desafios no perímetro irrigado de Morada Nova (PIMN), Ceará. Dissertação (mestrado). Pós-graduação em Geografia da Universidade Estadual do Ceará, 2006.

SANTANA, Eudoro. Entrevista. Conviver: uma revista de estudos avançados do semi-árido. Fortaleza, n 1 , p. 4-6, 2003.

SANTOS, J.D. Desenvolvimento rural, biodiversidade e políticas públicas: desafios e antagonismos no Pontal do Paranapanema - SP. Tese (doutorado em Ciências) Programa Recursos Florestais (Conservação de Ecossistemas Florestais). Universidade de São Paulo - USP. Escola Superior de Agricultura "Luiz de Queiroz” - ESALQ. Piracicaba - SP, 2012.

SCALOPPI, E.J. Sistemas de irrigação e seus componentes. Brasília, D.F.: ABEAS, 1988. 68p. Curso de Engenharia de Irrigação. Módulo 5.

SILVA, R.M.A. Entre o combate a seca e a convivência com o semi-árido: transições paradigmáticas e sustentabilidade do desenvolvimento. Tese (Doutorado) Centro de Desenvolvimento Sustentável, Universidade de Brasília. Brasília, 2006.

VASCONCELOS, T.S.L. Reestruturação Socioespacial do Ceará: os desdobramentos da modernização da agricultura no território do Perímetro Irrigado Baixo Acaraú. Dissertação (Mestrado Acadêmico em Geografia) Universidade Estadual do Ceará, Centro de Ciências e Tecnologia. Fortaleza, 2010. 